\title{
The developmental pattern of roots and shoots of oats under favourable conditions
}

\author{
J. J. Schuurman and J. J. H. de Boer \\ Institute for Soil Fertility, Haren-Groningen, the Netherlands \\ Received: 4 February 1970
}

\section{Summary}

A description is given of the developmental growth pattern of seminal and nodal roots of oats, regarded against the background of the process of shoot growth. The total weight of the nodal roots increased until the plant had attained its maximum length. Shoot weight, however, continued to increase. Individual nodal root development was smaller in accordance with later initiation.

Seminal roots and the early initiated nodal roots were the most important part of the root system. In the later part of the growth period the early formed nodal roots were more important on a weight basis than the seminal roots.

The growth of roots was interrupted in the week preceding the panicles becoming visible. In this week shoot growth hampered also. It is suggested that this is related with the plant's transition from the vegetative into the generative stage.

\section{Introduction}

The root system of cereal plants in the temperate zone consists of seminal and nodal roots. The seminal roots are initiated first from primordia in the seed using the reserve food in the seed. The nodal roots develop adventitiously from the basic nodes of the stem. Zijlstra (1939) mentions that nodal roots of oats initiated when the plant had two fully grown leaves. According to Goedewaagen (1942) the nodal roots of cereal plants in general initiate when one or more leaves are present. The reserve food in the seed is exhausted at this moment, making the growth of the nodal roots dependent from the process of photosynthesis. Little is known about the developmental pattern of the individual seminal and nodal roots and the rate of initiation of nodal roots. Weaver (1926) gives a short description in four developmental stages. Brenchley and Jackson (1921) carried out an investigation with barley and wheat but did not distinguish between seminal and nodal roots. Moreover they restricted themselves almost completely to root weights. Schulze (1911) also gave no morphological particulars but only weights and lengths. Gliemeroth (1957) mentions numbers, lengths and dry weights of 2-5 growth stages.

Knowledge of the development of the roots in subsequent stages is important for the understanding of the relation between root and shoot growth. Moreover it gives a key for the evaluation of the individual roots for the absorption of water and minerals, and at the same time of the significance of deviations. This study is an attempt to collect data on these topics. 


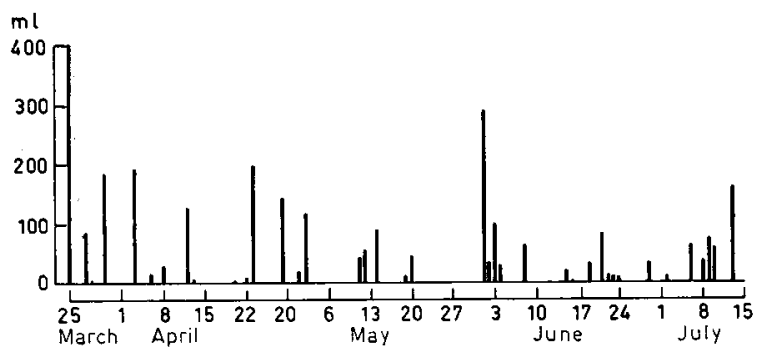

Fig. I Daily amounts of rain

\section{Materials and methods}

Asbestos tubes with a height of $75 \mathrm{~cm}$ and an inner diameter of $15 \mathrm{~cm}$ were filled with soil (Schuurman and Goedewaagen, 1965). The humus content of the soil was $3.7 \%$. The bulk density was 1.36 , corresponding with a pore space volume of $47.3 \%$. The tubes with the soil were placed in the open in a wire-netting cage, each one separately in a shallow dish. These dishes were filled with a layer of $5 \mathrm{~cm}$ of water, giving a soil-water level in the profiles at about $70 \mathrm{~cm}$ below soil level. The water content of the dishes was controlled regularly and water was replenished if necessary. In order to avoid evaporation of water from the dishes and leakage from rain into them, the dishes were covered with a plastic collar. Rainfall was measured (Fig. 1). From the quantities of water replenished, the precipitation and the water content of the soil the amount of water used by the plants was calculated.

Fertilizers were applied superficially. Each profile received $1.5 \mathrm{~g}$ fertilizer $12-10-20$, corresponding with about $1000 \mathrm{~kg}$ per ha.

The seed was sown on 24 March by means of a corkborer on a depth of $13 / 4 \mathrm{~cm}$. Two selected grains were laid out in each hole, after which the holes were refilled with soil. The surface of the profiles was covered with a $1 \frac{1 / 2}{\mathrm{~cm}}$ layer of gravel in order to restrict evaporation of moisture from the top layer of the profiles.

Air temperatures were recorded during the growth period of the plants by a selfrecording thermometer (Fig. 2).

Sampling in duplicate by weekly intervals started 13 May and was finished on 15 July. This means that at each sampling date two plants were removed from the experiment.

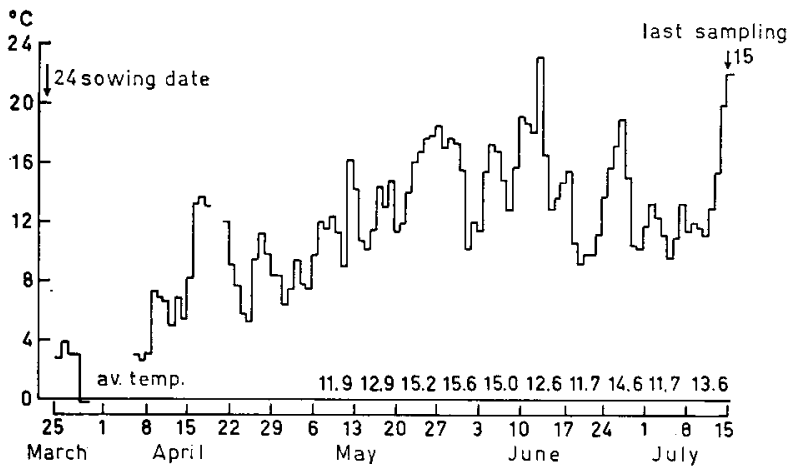

Fig. 2 Average temperatures per

Neth. J. agric. Sci. 18 (1970) 


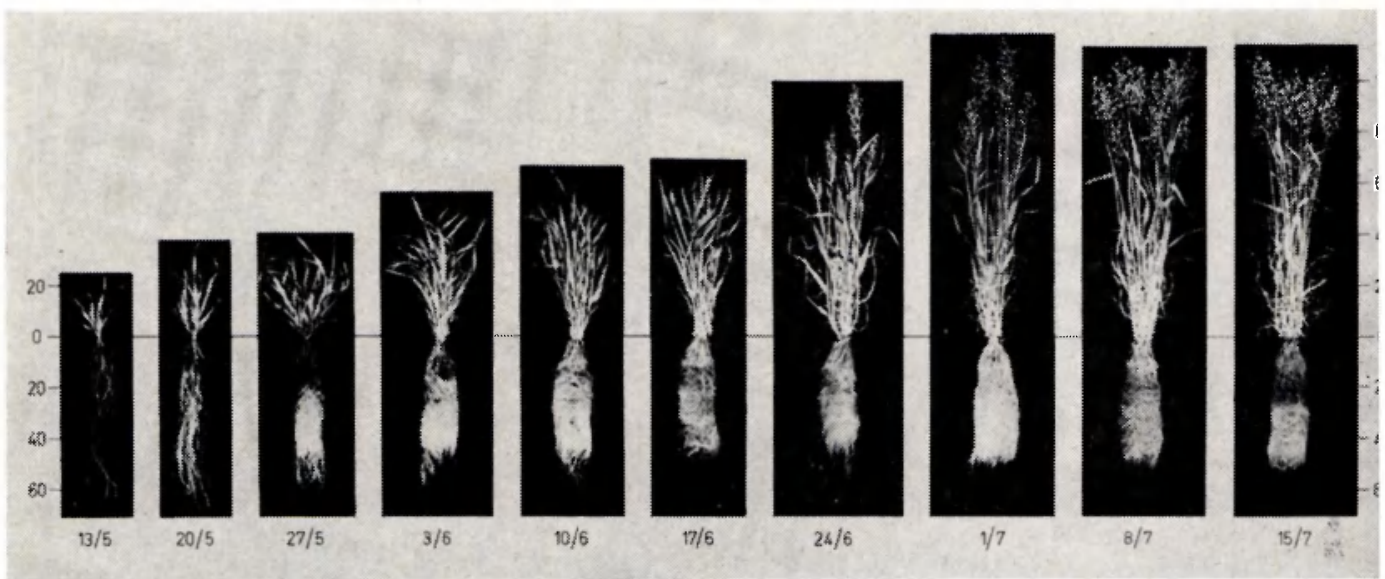

Fig. 3 Shoot and root growth of oats on humous sand

\section{Results and conclusions}

Shoots

On 14 April - three weeks after sowing - the seedlings emerged from the earth. Emergence was delayed due to low temperatures (Fig. 2). Save for a small number of exceptions the number of plants on each profile was 2. On 16 April one of these plants was removed. Fig. 3 illustrates the growth of shoots and roots.

Leaf formation. The second leaf became visible 6 days after the date of emergence. The third up to the eighth leaf followed at regular intervals. Leaf formation was finished at 26 May. This developmental pattern is greatly in accordance with Weaver's description (1926).

Tiller number. Tillering started simultaneously with the fourth leaf becoming visible. The number of tillers reached its maximum with an average of 22 . This was 7 weeks after emergence or 1 week after the last leaf becoming visible. After the beginning of flowering the number of living tillers per plant decreased by dying to an average number of 13 .

Panicle number. The first panicle from all plants was visible three weeks after the last leaf had become visible. The maximum number of panicles was present three weeks after the first panicle had become visible. The maximum number of panicles corresponded with the final number of tillers (Fig. 4).

Flowering. First flowering was observed about one week after the first panicle was present. This was somewhat earlier as had been found by Weaver (1926).

Length of the shoots. Growth was very regular. The maximum length was attained 11 weeks after emergence and about 5 weeks after the last leaf became visible. The 


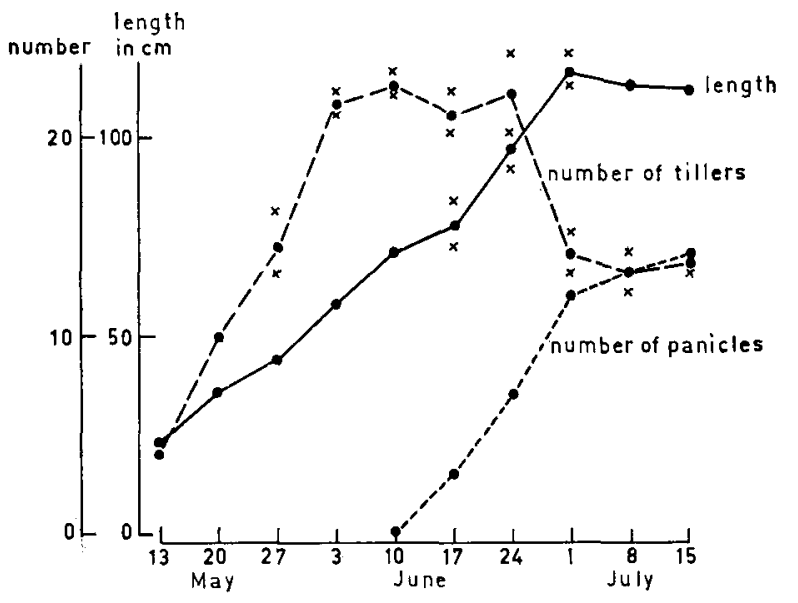

Fig. 4 Numbers of tillers, number of panicles and maximum length of shoots

maximum length was $116 \mathrm{~cm}$ (Fig. 4). This was considerably more than was found by Weaver (1926), but this may be have been effected by strain difference.

Fresh weights of the shoots. During the period from 13 May to 3 June the fresh weight doubled each week. In the following weeks the increase was constant. Finally, in the last week of the experiment from 8 to 15 July the weight decreased (Fig. 5).

Dry weights of the shoots. The increase in dry weight during the initial growth period was inferior to that of the fresh weights. In the final week the increase in dry weights was higher, due to moisture losses from the shoots (Fig. 5).

Percentages of dry matter in the shoots remained rather constant during the first weeks and increased regularly afterwards. An exception was found in the week pre-

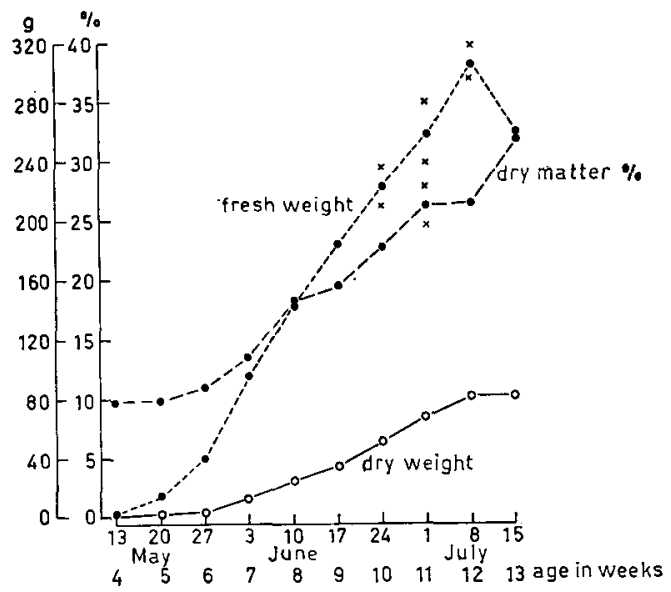

Neth. J. agric. Sci. 18 (1970)
Fig. 5 Weights and dry-matter contents of shoots 
ceding the panicles becoming visible. In this week the increase was distinctly lower. Hudig et al. (1914) found already in spring cereals a period of rest in the formation of dry matter, mostly coinciding with the moment of emergence of the ears or with the presence of the first ears. They assume that this interruption is of a physiological nature and is not caused by weather conditions. Van de Sande-Bakhuizen (1937) states: 'As soon as the flowering stage appears.... the relative water content of the plant decreases, dry weight increase is reduced temporarily...' Dilz (1964) mentions also a temporary decrease in the dry-matter formation, coinciding with flowering. Also in the week after the moment of reaching the maximum length on 1 July - meaning that vegetative growth had finished - the dry-matter percentage hardly increased (Fig. 5). Since the crop had not yet matured on the last sampling date (15 July) the dry-matter percentage would have increased furthermore.

\section{Roots}

At each sampling date one root system was carefully analysed. Comparison of these data from subsequent sampling dates shows the pattern of the growth of the roots. Only 8 July was omitted since the differences between 1 and 15 July were minimal. After extricating the roots the seminals and nodals were counted, whereafter the nodal roots were divided into groups according to age.

\section{Total root mass}

Total dry weight. There was a strong increase in dry weight of the roots from the first sampling date (13 May) until 10 June. Between 10 and 17 June the root weight did not increase. It may be emphasized that this occurred again in the week preceding the presence of panicles. Brouwer (1959) mentions also a leveling of the dry-matter formation of pea roots, coinciding more or less with flowering. According to Dilz (1964) root-weight increase of oats proceeded regularly until the end of June. From

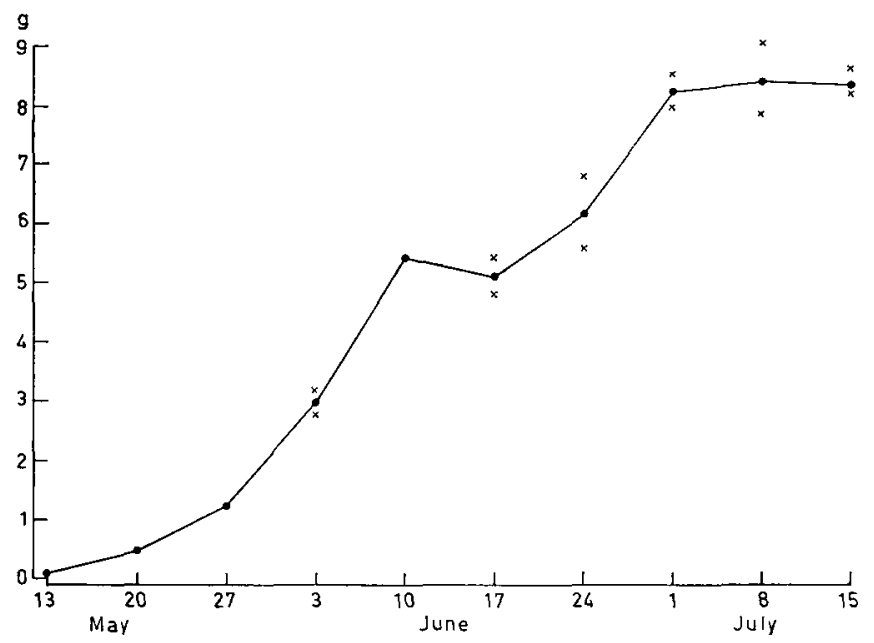

Fig. 6 Total dry root weight per plant 


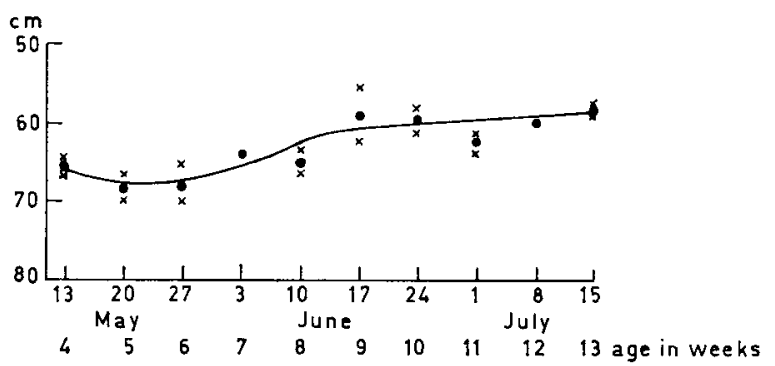

Fig.7 Maximum rooting depth with increasing age

this time root weight remained more or less constant. However in his experiment the plants were growing on a culture solution.

After 17 June the weight of the roots in our experiment showed another increase until 1 July. Root growth stopped at the very moment of reaching the maximum length of the shoots (Fig. 6). According to Schulze (1911) root growth stopped during emergence of the ears.

Rooting depth. This was determined during the process of washing which was one of the reasons to start at the bottom of the profile. Maximum rooting depth was recorded when the first root tip became visible.

At the first sampling date (13 May) the maximum rooting depth was not yet attained. This was found to be the case on 20 May, about 36 days after emergence and almost simultaneously with the becoming visible of the final leaf (Fig. 7). This was clearly differing from the findings of Weaver (1926), who found maximum rooting depth when plants were beginning to blossom. After 27 May depth of rooting became gradually smaller, without evidence for the cause of this phenomenon. Until the end of May the deepest penetrated roots were seminal roots.

\section{Seminal roots}

Number. Per plant the number of seminal roots varied between 4 and 5 , in only one case it was 6 . The majority of the plants had 4 seminal roots. This number was present already on the first sampling date and presumably earlier. Zijlstra (1922) found an average of 3 with oats grown in soil. In addition to the data of oats Zijlstra gives data of other cereals. According to Philipp (1954) the number of seminal roots of oats varies between 3 and 6 . It may be concluded from these data that there is in general little variation in seminal root number.

Total weight. Increase of weight of seminal roots after the first sampling date (13 May) until 27 May was considerable. This increase was followed by a decrease in the next week. This, however, cannot be seen as an indication of a total stop of root growth, since the number of nodal roots was doubled in this week. The seminal roots had reached their maximum weight just after the end of tillering and before the panicles became visible. The maximum point shown in Fig. 8 is probably too high when the difference between the duplicates is taken into account. From this date the weight decreased rapidly. It may be clear that - accounting for the constant number, the simultaneous initiation and the similarity of the ultimate habitus - the growth rate of the individual seminal roots will have paralleled greatly the picture in Fig. 8. 


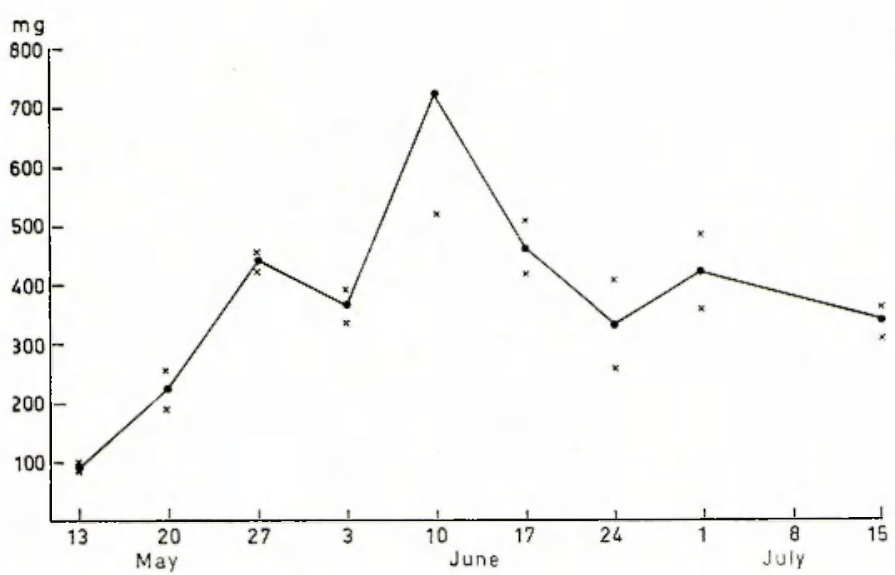

Fig. 8 Total weights of seminal roots per plant

Detail description of the seminal roots. On the first sampling date the length of the longest root was $66 \mathrm{~cm}$. Branch root formation had taken place from the base to $20 \mathrm{~cm}$ from the tip. The greatest length of the first order branch roots was $30 \mathrm{~cm}$ (Fig. 9).

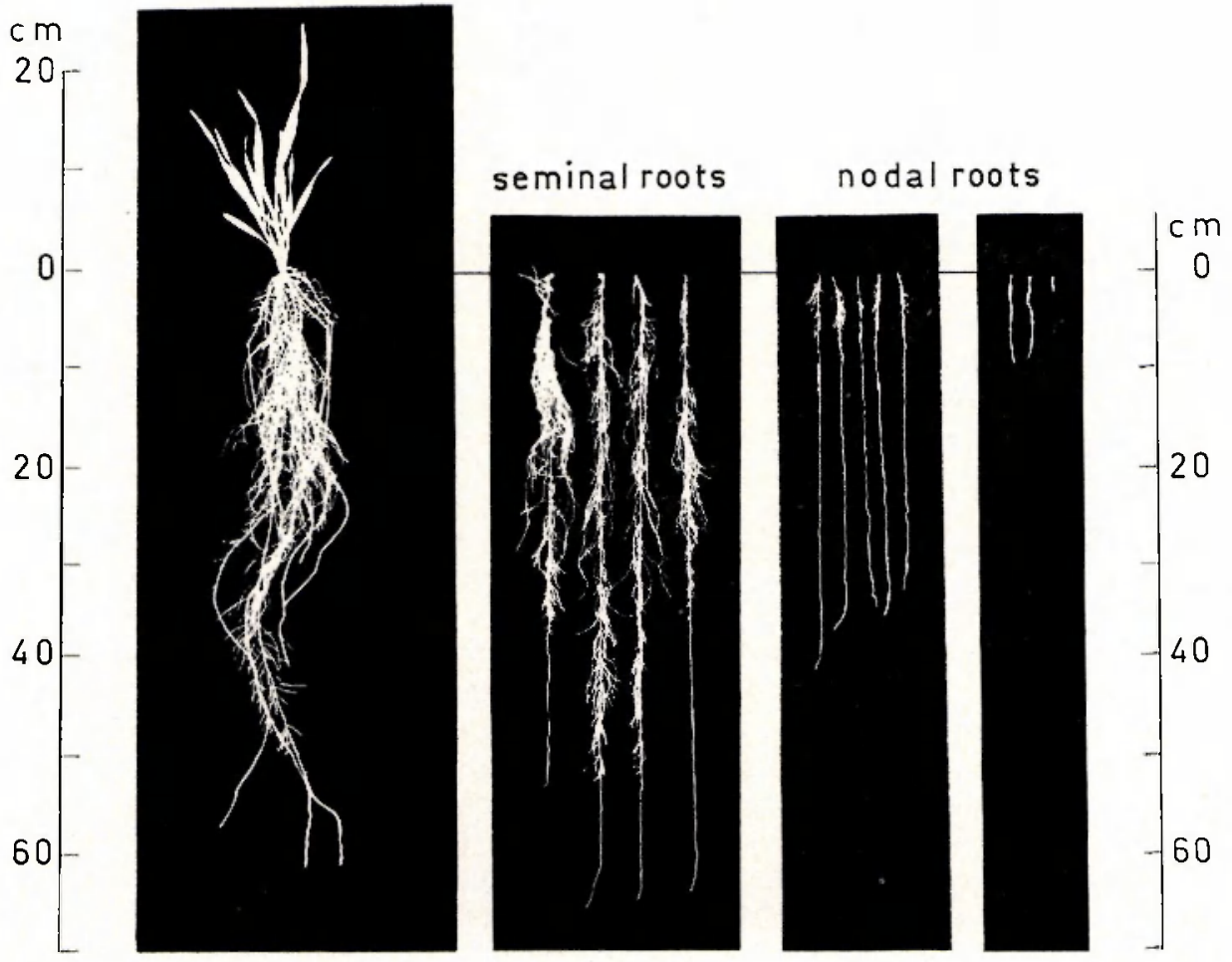

Fig. 9 Shoot and roots of the plant on 13 May 


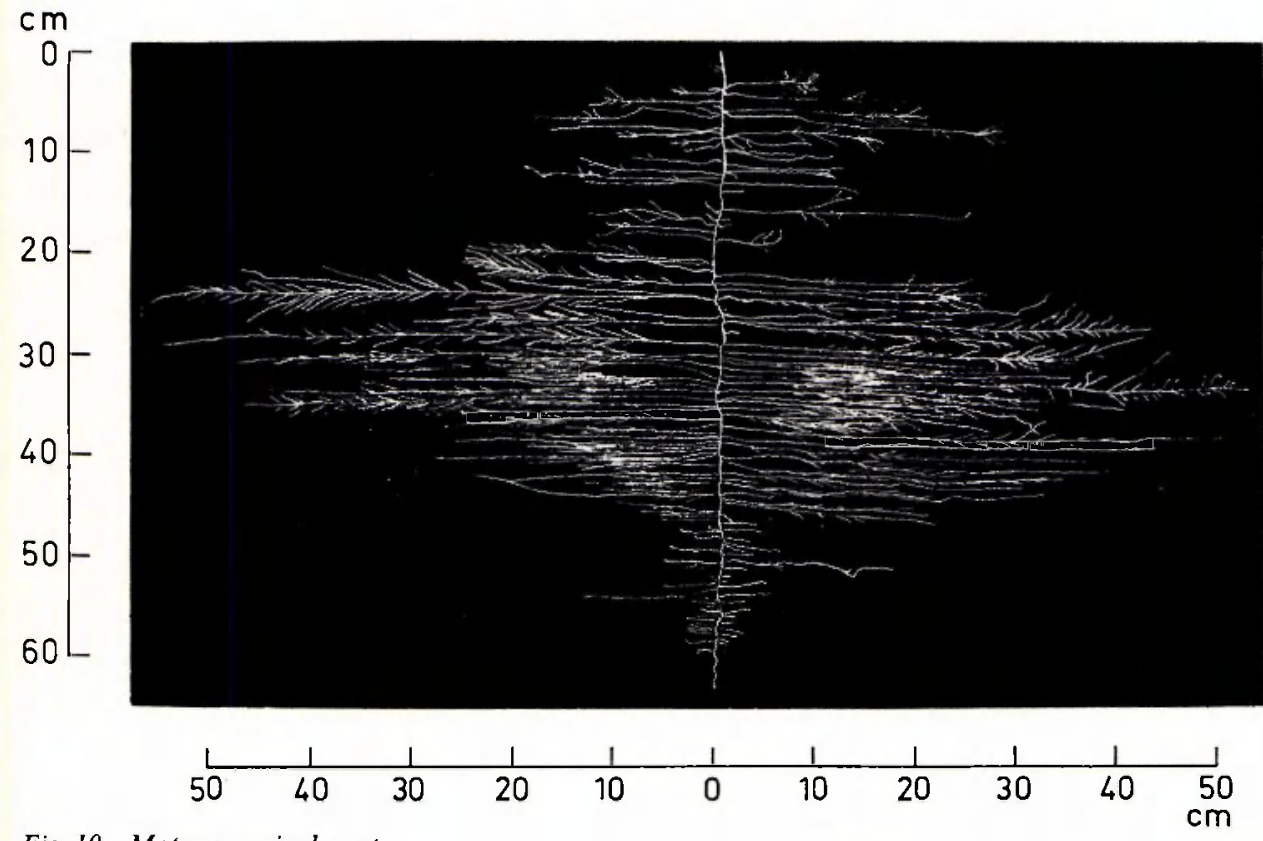

Fig. 10 Mature seminal root

On 20 May the maximum length had increased to $70 \mathrm{~cm}$, being the maximum that was attained during the plant's life, probably due to the presence of a water table at a depth of $70 \mathrm{~cm}$ below soil level. Branch-root formation had proceeded to $10 \mathrm{~cm}$ from the tip. The longest first-order branch root had a length of $40 \mathrm{~cm}$.

By the end of the next week, until 27 May, branch roots had been formed along the whole length of the primary root. The longest first-order branch root had a length of $52 \mathrm{~cm}$. This is in strong contrast with Weaver (1926), who stated a maximum length of first order branch roots of oats of $12.5 \mathrm{~cm}$, but here elongation of main roots continued longer. Troughton (1962) gives data for other cereals. On 27 May the firstorder branch roots in the top layer of $25 \mathrm{~cm}$ were covered with small numbers of second-order branch roots. Below a depth of circa $30 \mathrm{~cm}$ the first-order branch roots were longer. These roots had formed liberal numbers of second-order branch roots. Full growth of the seminal roots on a weight basis was attained by 10 June (Fig. 10). The seminal roots remained present until the end of the growth period studied and did not show any sign of heavy deterioration. As early as 1921 this was already stated by Percival, in 1922 by Zijlstra and in 1957 by Gliemeroth. Nevertheless, the opinion can be found in various later publications, that the at least the main seminal would die in early stages of the plant's life (Walther, 1947; Philipp, 1954).

\section{Nodal roots}

Number. On each sampling date the numbers of nodal roots of two plants were averaged. On 13 May the average number of nodal roots per plant was 10 . The plants had 4 tillers and 5 leaves at that date. These root numbers are in accordance with 


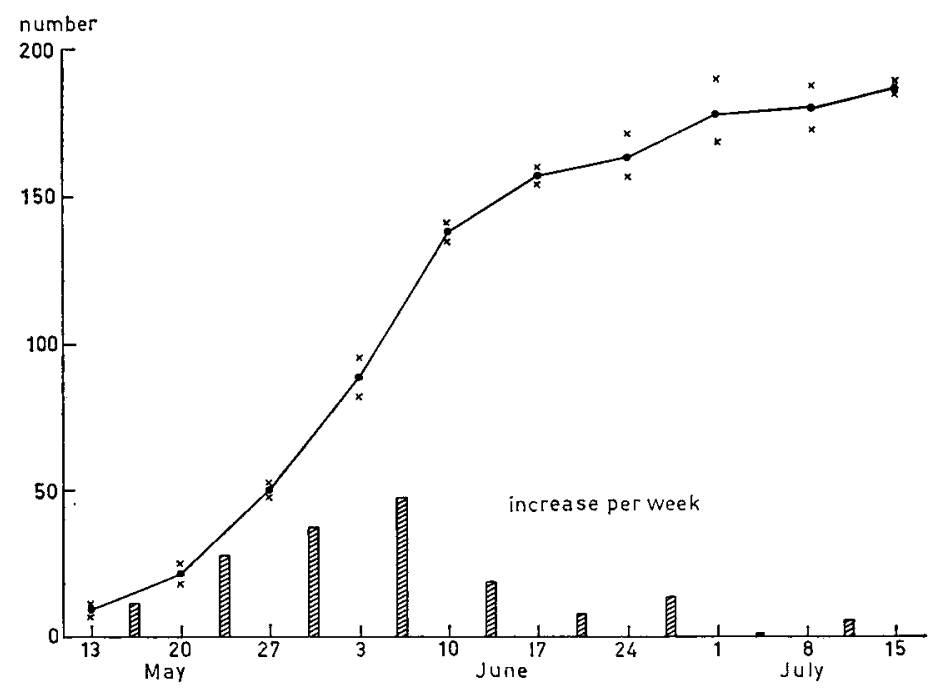

Fig. 11 Average number of nodal roots per plant with increasing age

Weaver's (1926) statements. In the following 4 weeks this number increased with increasing numbers per week. The greatest number of nodal roots was initiated in the week of 3-10 June. This was between the end of tillering and the beginning of panicle emergence. Nodal root initiation proceeded until the end of the experiment on 15 July, but the numbers initiated per week decreased gradually (Fig. 11). The conclusion can be drawn that nodal root formation in general proceeds according to an optimum curve. Percival (1921) noted that winter wheat formed nodal roots until the end of May or June. It may be questioned, the point of regression in the nodal root formation being just before the emergence of panicles, if this is the point of transition from vegetative into generative stage (van de Sande Bakhuizen, 1937). The total number of nodal roots at the end of the experiment amounted to an average of 184. This number exceeds those found by Zijlstra (1922) with winter wheat and Goedewaagen (1942) with oats. These differences may be ascribed partly to better growth conditions as Goedewaagen (1942) stated that the number of nodal roots under conditions of agricultural practice was lowered as a consequence of competition. Assuming that all tillers have formed roots, the average number per tiller was 8 . Possibly, however, only tillers that remained alive formed roots. In that case the average number was 14 .

Total weight. The nodal root weight increased slowly until 27 May. From this date until 10 June growth was strongly accelerated (Fig. 12). There was no increase in weight during the week from 10-17 June, even though new nodals were initiated during this week (Fig. 11). From 17 June to 1 July root weight increased again considerably. Increase of root weight stopped when the plants had attained maximum length. It may be seen here, that the presumable transition from the vegetative in the generative stage influenced root growth. According to Kmoch (1961) the root weight of winter wheat multiplied between the moment of shooting of the plant and emergence of ears. With the oats in our experiment the increase in this period was even greater. 


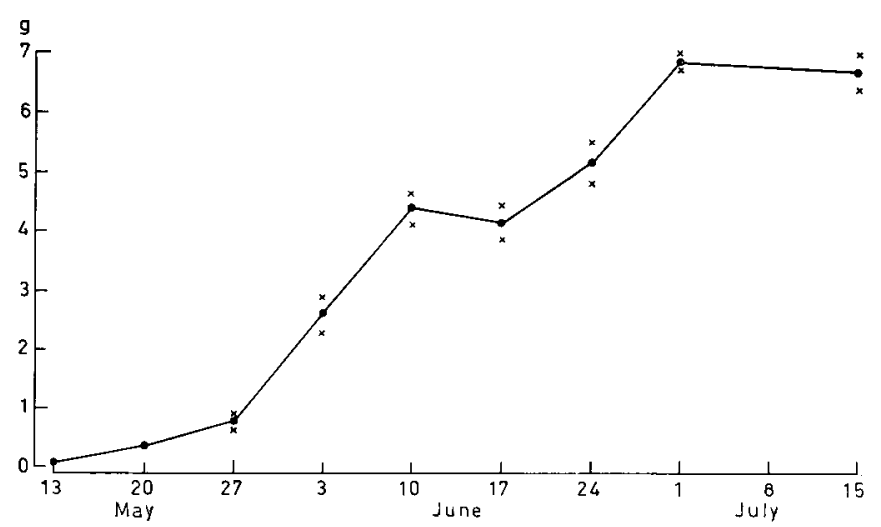

Fig. 12 Total weight of nodal roots

Detail description of the nodal roots. Considerable differences in habitus between the roots were found. It may be questioned if these differences are determined solely by differences in time of initiation. Since the habitus of later initiated roots cannot be found in developmental stages of earlier formed roots, it may be assumed that the greater numbers of nodal roots initiated in the later weeks must have played a part, probably accompanied by changes in the soil.

On the basis of length of the main root and the rate of branch-root formation the roots in the sample of 13 May could be divided into two groups (Fig. 9). It was clear that these groups were of a different age. In the week from 13-20 May the number of roots increased. From the roots on 20 May firstly those were selected which must have been present on 13 May on the basis of the numbers of 13 May. The remaining roots were assumed to have initiated after 13 May. In general these were easily recognizable on a basis of length. Slight variations in number were considered accept-

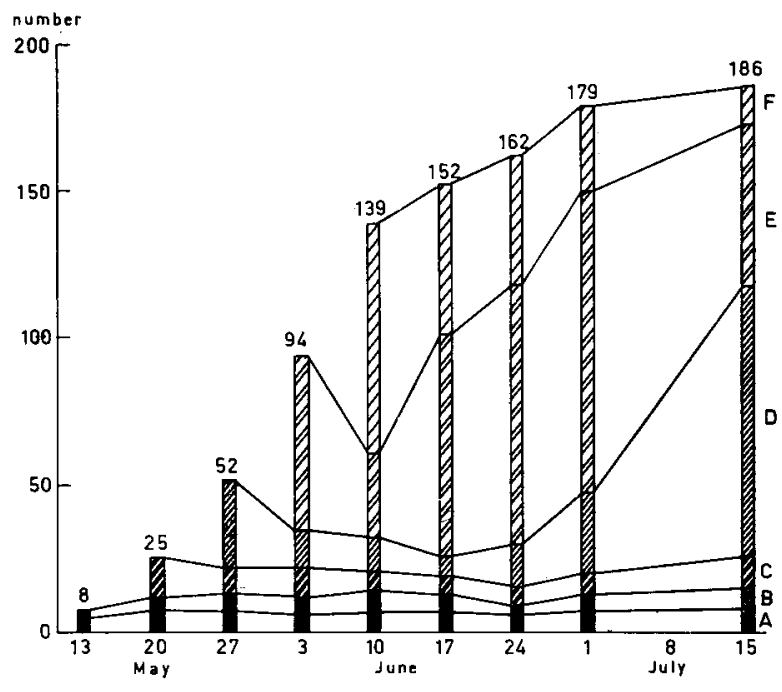

Fig. 13 Numbers of nodal roots in groups with increasing age of the plant 
able because of individual variations of the plants. At the end of every week in principle a group was added on the basis of age. This, however, did not hold true for a division on the basis of habitus. Despite of difference in age in later formed roots often the same habitus occurred as in earlier formed ones. In total six habitus groups could be distinguished (Fig. 13). It is clear that especially the two groups of nodal roots, distinguished on 13 and 20 May, remained continuously recognizable. On 1 July the roots attained their maximum weight (Fig. 12). It may be assumed that the individual roots on this date were developed maximally. It is evident from Fig. 14 that the earliest initiated nodal roots had attained the biggest size, which was comparable with that of the seminal roots. The size of the roots decreased in general, according to the time of their initiation. In contrast with our findings Gliemeroth (1957) recorded a much lesser development of the nodals as compared with the seminals. The early roots, even though their number is small, were very important for the plant owing to their deep penetration and their formation of many and long branch roots. This holds true also for the seminal roots. This conclusion is supported especially for the nodal roots and to a lesser degree for the seminal roots by their big share in the total root weights (Fig. 15). It appears from this figure that the seminal roots were most important during a short incipient period on a weight basis. The portion of the seminal roots in the total root weight decreased rapidly, however, and from the end of May the nodal roots dominated. These findings are supported to a certain extent by those from Sallans (1942), who stated that the seminal roots of spring wheat were the most important part of the root system until half-way the growing season, 'constituting the chief absorbing system'. According to Brouwer (1962) the share of the seminal roots in the total root weight amounts in general to less than $5 \%$ and often does not ex-

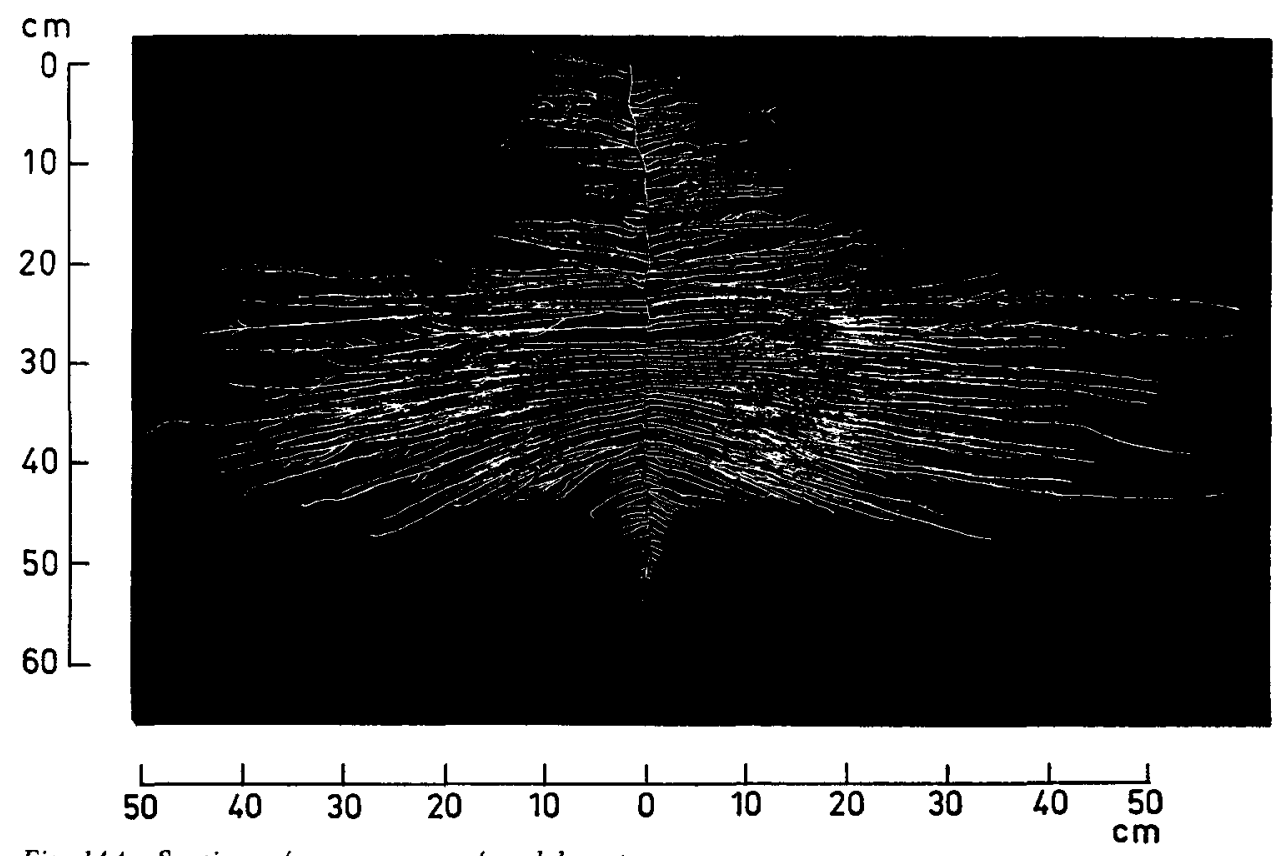

Fig. 14A Specimen from a group of nodal roots 

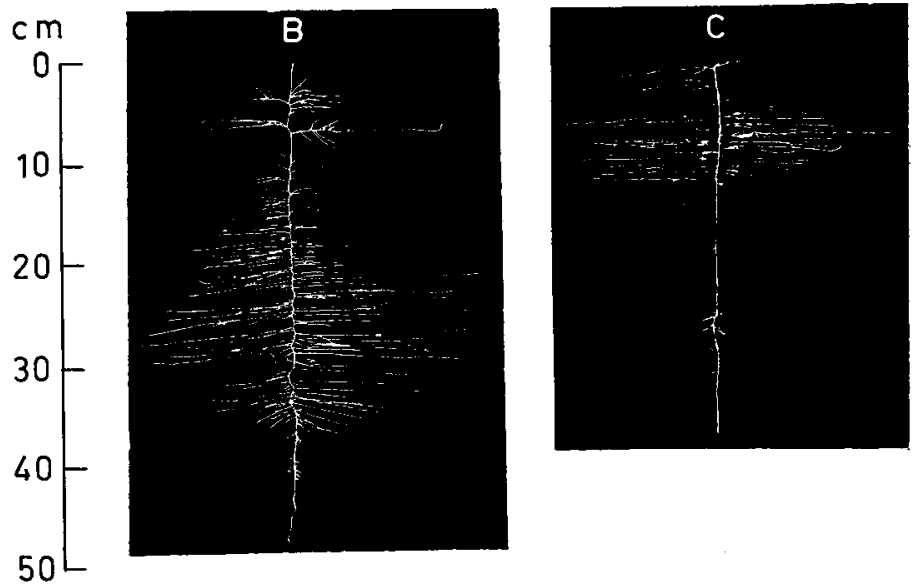

Fig. 14B-F Specimens from groups of nodal roots
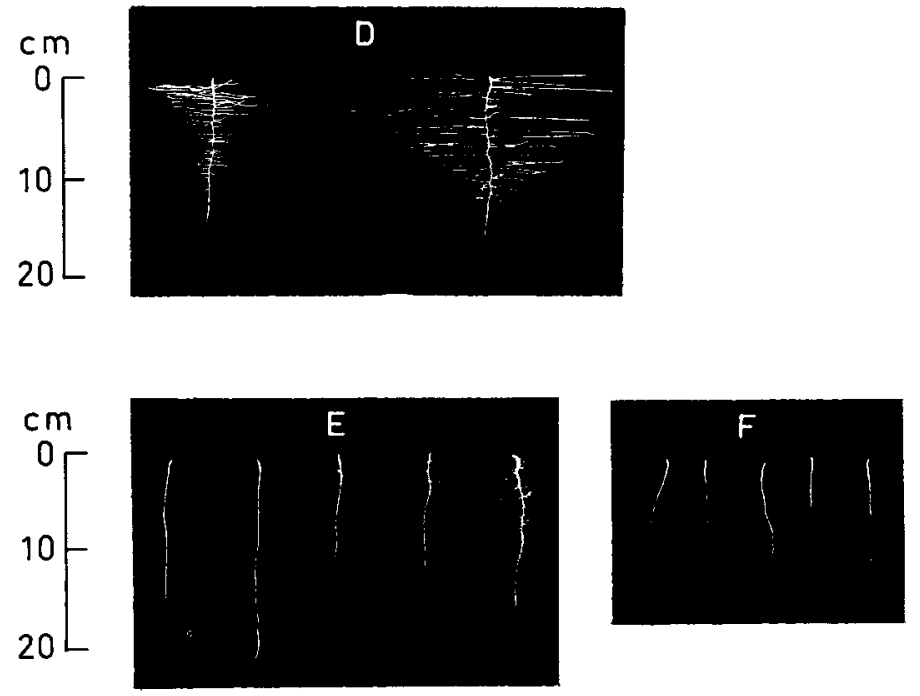

ceed $1 \%$. In our experiment this percentage was 5 on 24 June and remained more or less constant afterwards. This is in contrast with the findings of Gliemeroth (1957), who found in the flowering stage $69.3 \%$ seminal roots in the total root weight and in mature plants $50 \%$.

The opinion of Goedewaagen (1942) and Troughton (1962) regarding the presence of two groups of nodal roots, one type being long and profusely branched and the other long, thick and sparsely branched, is not confirmed by this investigation. In fact there are more types (Fig. 14) which partly merge gradually into another. Troughton (1962) leaves this possibility open already by speaking of intermediate types, but this actually does not cover our findings. Our results are in good accordance with those of Percival (1921) and Jackson (1922) insofar they state that the early nodal roots are thin and well-branched, whereas the later formed ones are thicker and possibly not branched that much, initially. 


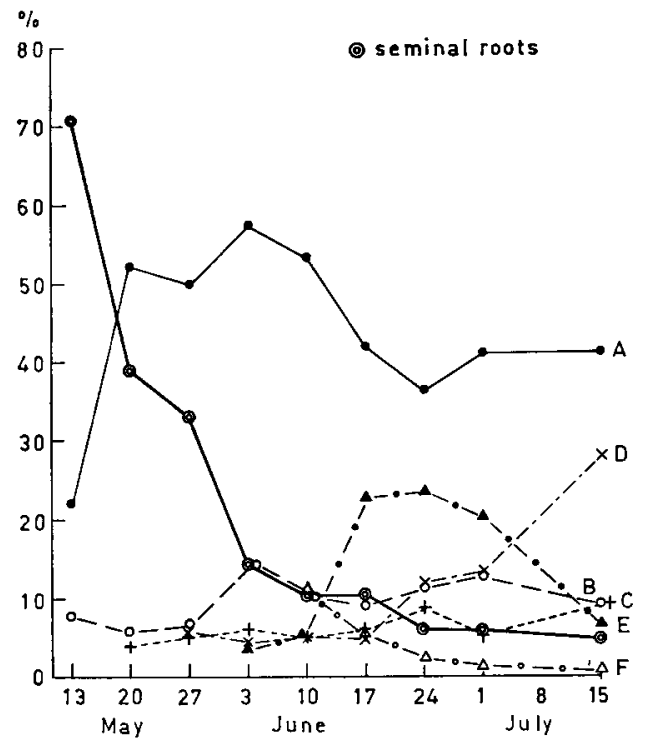

Fig. 15 Weights of seminal and nodal roots in $\%$ of total root weights

Shoot/root ratios

It appears from Fig. 16 that the shoot/root ratio increased slowly in the initial growth period, but then made a jump between 10 and 17 June. This was due to the fact that the root weight did not increase in this week whereas the shoot weight did. This is

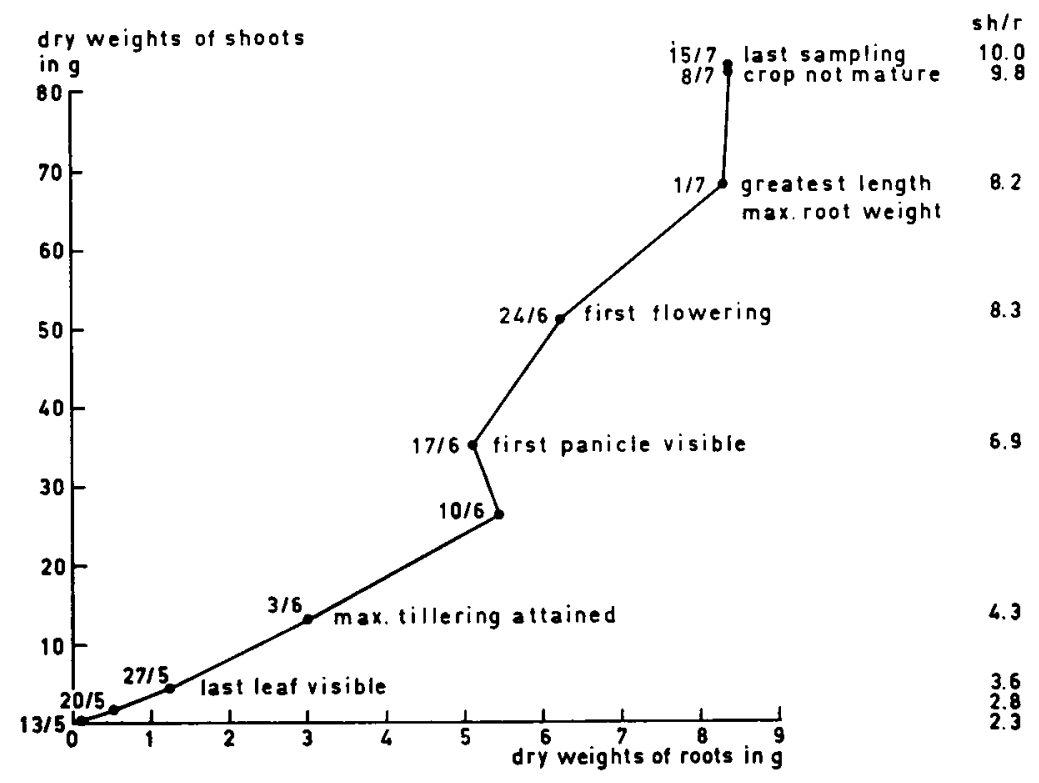

Fig. 16 Relation between shoot and root growth 
the phenomenon that was mentioned before with the question if it were connected with the plant's transition from the vegetative into the generative stage, as has been described by Brouwer (1962) and others. From 17 June until the end of the root growth on 1 July the shoot/root ratio increased again regularly. In the last weeks it increased strongly as a consequence of increase of dry matter in the shoot. During flowering the shoot/root ratio was about 8 . Dilz (1964) found with oats on culture solution in this stage a ratio 10 .

From the development of the shoot/root ratios it is found that root growth precedes shoot growth. This was already stated by Schulze as early as 1911 , and later on by Bergmann (1954). It is demonstrated also by the relative increase of roots and shoots in the period between the beginning and the end of the growth period.

\section{References}

Bergmann, W., 1954. Wurzelwachstum und Ernteertrag. Z. Acker- u. PflBau 97: 337-368.

Brenchley, W. E. \& V. E. Jackson, 1921. Root development in barley and wheat under different conditions of growth. Ann. Bot. 35: 533-556.

Brouwer, R., 1959. De invloed van de temperatuur op de ontwikkelingscyclus van erwten. Jaarb. Inst. biol. scheik. Onderz. LandbGewass. 1959: 17-26.

Brouwer, R., 1962. Distribution of dry matter in the plant. Neth. J. agric. Sci. 10: 361-376.

Dilz, K., 1964. Over de optimale stikstofvoeding van granen. Thesis, Agricultural University, Wageningen. Also: Versl. landbouwk. Onderz. 641, pp. 134.

Gliemeroth, G., 1957. Untersuchungen über Ausbildung und Leistung der Keim- und Kronenwurzeln bei Sommergetreide. Z. Acker- u. PflBau 103: 1-21.

Goedewaagen, M. A. J., 1942. Het wortelstelsel der landbouwgewassen. Alg. Landsdrukkerij, 's-Gravenhage, pp. 173.

Hudig, J., C. Meyer \& H. R. Leemhuis, 1914. Groeiwaarnemingen bij graanplanten in de jaren 1909, 1910, 1911 en 1912. Versl. landbouwk. Onderz. Rijkslandbouwproefstns 15: 7-73.

Jackson, V. G., 1922. Anatomical structure of the roots of barley. Ann. Bot. 36: 21-39.

Kmoch, H. G., 1961. Die Herstellung von Wurzelprofilen mit Hilfe des Utah Erdbohrers und ihre Ausdeutung 3. Die Durchwurzelung verschiedener Bodentypen durch Weizen und Roggen. $Z$. Acker- u. PflBau 113: 342-360.

Percival, J., 1921. The wheat plant. A monograph. Duckworth, London, pp. 463.

Philipp, L., 1954. Ein Beitrag zur Morphologie der Wurzel von Avaena sativa L. Z. Acker- u. PflBau 97: 71-100.

Sande-Bakhuizen, H. L. van de, 1937. Studies on wheat grown under constant conditions. California Food Research Institute, Stanford University, pp. 400.

Schulze, B., 1941. Wurzelatlas. Paul Parey, Berlin.

Sallans, B. J., 1942. The importance of various roots to the wheat plant. Scient. Agric. 23: 17-26.

Schuurman, J. J. \& M. A. J. Goedewaagen, 1965. Methods for the examination of root systems and roots. Pudoc, Wageningen, pp. 86.

Troughton, A., 1962. The roots of temperate cereals (wheat, barley, oats and rye). Commonwealth Bureau of Pastures and Field Crops, Mimeographed Publ. No. 2/1962.

Walter, H., 1947. Die Grundlagen des Pflanzenlebens. Eugen Ulmer, Stuttgart, pp. 474.

Weaver, J. E., 1926. Root development of field crops. McGraw-Hill, New York, pp. 291.

Zijlstra, K., 1922. De hoofdwortel van enige graansoorten. Versl. landbouwk. Onderz. 26: 19-59.

Zijlstra, K., 1939. Onderzoekingen over de eerste ontwikkelingsperiode der jonge graanplant. Versl. landbouwk. Onderz. 45(17)A : 439-493. 